\title{
EFFECT OF REIKI ON PERCEIVED STRESS AMONG SOFTWARE PROFESSIONALS IN BANGALORE, INDIA
}

\author{
Saumya Suresh Vasudev ${ }^{1 *}$ and Shailaja Shastri ${ }^{2}$ \\ ${ }^{1}$ Ms., Jain University, INDIA, saumyasureshvasudev@gmail.com \\ ${ }^{2}$ Prof. Dr., Jain University, INDIA, shaila.s2003@gmail.com \\ ${ }^{*}$ Corresponding author
}

\begin{abstract}
The present study aimed to examine the efficacy Reiki on Perceived Stress among software professionals. The effect of Hands on reiki, Distance reiki and Distance reiki placebo was investigated in this study.120 software professionals from a software firm situated at Bangalore who met the inclusion exclusion criteria were taken up for the study. Sample was divided into four groups, hands on reiki group, distance reiki group, distance reiki placebo group and one control group (30 participants in each group). Hands on reiki and distance reiki healing were done for participants in the respective experimental groups for 5 minutes daily over 21 days. Distance reiki placebo group was not given any healing; the participants were just assured to be healed. Pre and post assessment was done for all three experimental groups. The control group was not given any intervention program however; the control group was assessed at two time intervals- pre and post assessment. The obtained data was analysed using descriptive statistics, ANOVA and paired t-test to assess statistically significant difference within the group and between the groups before and after assessment. The results of the study reveal that there is significant reduction in perceived stress for the hands on reiki group and the distance reiki group. There was no significant change in the perceived stress levels of the distance reiki placebo group and the control group from pre to post assessment.
\end{abstract}

Keywords: Perceived Stress, Reiki, Hands on Reiki, Distance Reiki and Distance Reiki Placebo, Software Professionals.

\section{INTRODUCTION}

Perceived stress at the workplace has gained a lot of importance in recent years. It is often described as the outcome variable measuring the experienced level of stress as a function of objective stressful events, coping processes and personality factors (Augustine et al, 2011). Research has shown a huge spectrum of potential sources of stress at the workplace. These sources of stress are environmental factors like economic problems, political turmoil, technological upheaval etc., organizational factors like job role and task demands, interpersonal demands, organisational hierarchy, scalar chain, organization's growth stage etc. and individual factors like family issues, financial problems, personality traits etc. (Robbins,2001). Despite the different array of stressors employees are faced with, helping them combat stress is a tedious job from the organisational point of view. Over time various stress management programs have been tried and tested and the effects are seldom long lasting as the programs may not cater to the specific requirements of the employees as the workforce is always heterogeneous in India. In recent times, there has been a huge shift of the type of stress management programs being used in software companies. Owing credit to massive 
research being done on the efficacy of complementary and alternative medicine (CAM), incorporation of CAM has paved its way into successful stress management techniques. Ranging from meditation to Ayurveda software companies are using a wide spectrum of CAM for its workforce. Reiki is also a CAM, it is a traditional Japanese healing modality categorized as energy medicine or biofield therapy by the National Centre for Complementary and Alternative medicine (NCCAM). Reiki practitioners help their patients to heal by placing their hands slightly above or lightly touching the patient's body at specific points. This is known as Hands on Reiki. By doing this the Reiki practitioner is channelling life force energy through his/her body into the body of the patient. This allows the body's natural healing energy to flow freely thereby facilitating healing (Barnett et al,2014). Reiki can also be passed as Distance Reiki where in the patient and the Reiki practitioner is not in each other's vicinity. The Reiki practitioner mentally visualises the patient and heals the latter. Distance Reiki is usually used when the patient is unable to meet the Reiki practitioner Reiki has most often been used for memory loss, anxiety, depression, pain management and also in growing frequency with terminally ill patients suffering from cancer and AIDS. There is a lot of debate pertaining to the assumption that Reiki healing could just be a placebo effect. Although research involving Reiki as an energy healing therapy has not been extensive, the present study is being conducted to test whether Reiki can reduce Perceived Stress of Software professionals.

\section{OBJECTIVES}

To study the efficacy of Hands on Reiki (H-Reiki), Distance Reiki (D-Reiki) and Distance Reiki Placebo (D-R placebo) in reducing perceived stress among software professioanls.

\section{HYPOTHESES}

- Primary Hypothesis: Reiki has no significant effect in reducing perceived stress of software professionals.

- Sub Hypotheses:

i. Hands on Reiki has no significant effect in reducing perceived stress of software professionals.

ii. Distance Reiki has no significant effect in reducing perceived stress of software professionals.

iii. Distance Reiki Placebo has no significant effect in reducing perceived stress of software professionals.

\section{RESEARCH DESIGN}

Experimental design was adopted in this study.

\section{METHOD}

\subsection{Participants / Sampling}

The data for the study was collected in Bangalore from IT companies for software professionals with complaints of high stress. The sample of software professionals was taken from Bangalore only based on the inclusion and exclusion criteria. The sample size was one hundred and twenty. Thirty participants each was randomly assigned to the three experimental groups (hands on reiki group, distance reiki group and distance reiki placebo group) the control group.

\subsection{Inclusion Criteria}

i. Male and Female software professionals.

ii. Age 23 to 34 years.

iii. Ability to comprehend and write in English.

iv. Minimum of 12 months' work experience in an organisation.

v. Minimum educational qualification- Bachelor of Engineering/Bachelor of Technology/ BCA/ BSC Computer science

vi. Employed in the IT industry.

\subsection{Exclusion Criteria}

i. Presence of any chronic physical ailment or psychiatric disorder. 
IJASOS- International E-Journal of Advances in Social Sciences, Vol.II, Issue 6, December 2016

ii. Previous exposure to any behavioural intervention within the past 12 months.

\subsection{Materials/Tools of the study}

i. Socio-demographic Data Sheet: This form contained information such as name, age, sex, education, marital status and family type, nature of work and years of experience and any significant physical illness.

ii. Stress inventory for gathering background information about stressors faced by software professionals. (Verma, M;2001)

iii. Perceived Stress Scale (PSS) (Cohen, et al., 1983): Developed by Cohen, et al., (1983), is a global scale and identifies the factors influencing or influenced by stress appraisal. It is a 14 -item scale which measures the degree to which situations in one's life is appraised as stressful during the past month. There are seven negative and seven positive questions for which the subjects were required to choose from a scale of 5 alternatives 'never' 'almost never' 'sometimes' 'fairly often' 'very often' relating to their feeling of being stressed on a 0-4 scale. The 7 positive items were reverse scored and added up to the 7 negative items to get the total score. Higher scores indicate greater stress. PSS scores are obtained by reversing the scores on the 7 positive items (e.g. $0=4,1=3,2=2$ ) and then summing across all 14 items. Items 4, 5, 6, 7, 9, 10 and 13 are the positively stated items. Coefficient alpha reliability for PSS is 0.84 with a test retest correlation of 0.85 .

\subsection{Statistical tools}

Individual variables were coded for computer analysis and analysed using Statistical Package for Social Sciences (SPSS). The obtained data was analysed using descriptive statistics, ANOVA and paired t-test to assess statistically significant difference within the group and between the groups before and after assessment.

\subsection{Procedure}

The investigator gave a detailed explanation about reiki (in person) to the hands on reiki group and (sent a mail explaining the same) to the distance reiki group and distance reiki placebo group. Participants belonging to the distance reiki group and distance reiki placebo group did not meet the experimenter in person. All experimental groups were given the pre assessment tools, hands on reiki had a paper pencil pre assessment whereas distance reiki and distance reiki placebo group had online pre assessment of the same tools. After the pre assessment the experimental groups were given reiki intervention for twenty-one days, hands on reiki and distance reiki was given to the participants of the respective groups by the experimenter. For the distance reiki placebo, the participants were assured that the intervention would be given, however no distance healing was given to induce the placebo effect. After 21 days, post assessment was done for all the experimental groups. The Control Group was not given any intervention however orientation to the study and their importance as a control group was communicated to those who provided their consent to be a part of the control group. Both the tools were administered on the group. The group was again assessed after 21 days (post assessment).

\section{RESULTS}

Background information: The sample consisted of 120 Software IT professionals aged between 23 to 34 years. The sample had participants with age group ranging from 23 to 34 . All participants had a minimum of 12 months of work experience. The average work experience was 4 and half years and the maximum work experience were 12 years. The minimum family size was 2 and the maximum was 8 . The sample reported to suffer highest from stressors pertaining to their work. The major sources of stress were poor relations with superiors, lack of support from superiors, difficulty in maintaining relationship with superiors, unfair assessments by superiors, discrimination and favouritism, working with uncooperative colleagues, working with incompetent colleagues, jealousies and competition among colleagues, time pressure and deadlines, work overload, fear of making mistakes that can lead to serious consequences, work is mentally straining, having to work continuously to achieve self-set targets, feeling inadequate for the job, task monotony, felling of being underpaid, lack of promotion aspects, feeling insecure in the job and fear of becoming redundant. The groups had similar views and beliefs about complementary and alternative medicine (CAM). The sample was aware about the benefits of various CAM modalities. On the contrary the sample did not have bare minimum knowledge of Reiki and its healing potential.

The results have been obtained after the collected data was scored and put to statistical analysis in order to test the formulated hypothesis of the study. 
IJASOS- International E-Journal of Advances in Social Sciences, Vol.II, Issue 6, December 2016

Table 1: Mean baseline scores of the four groups on the variable of perceived stress at pre-intervention level

\begin{tabular}{|c|c|c|c|c|c|c|}
\hline \multicolumn{7}{|c|}{ Descriptives } \\
\hline \multicolumn{2}{|c|}{} & N & Mean & SD & Minimum & Maximum \\
\hline $\begin{array}{c}\text { Perceived } \\
\text { Stress. Pre- } \\
\text { intervention }\end{array}$ & H - Reiki & 30 & 30.07 & 6.812 & 18 & 48 \\
\cline { 2 - 7 } & D-Reiki & 30 & 26.27 & 5.759 & 14 & 37 \\
\cline { 2 - 7 } & D-R Placebo & 30 & 29.53 & 7.262 & 16 & 46 \\
\cline { 2 - 7 } & Control & 30 & 28.23 & 7.147 & 11 & 40 \\
\hline
\end{tabular}

Table 2: Shows the F ratio for perceived stress at pre intervention level

ANOVA

\begin{tabular}{|c|c|c|c|c|c|c|}
\hline \multicolumn{2}{|c|}{} & $\begin{array}{c}\text { Sum of } \\
\text { Squares }\end{array}$ & df & $\begin{array}{c}\text { Mean } \\
\text { Square }\end{array}$ & F & Sig. \\
\hline $\begin{array}{c}\text { Perceived } \\
\text { Stress. } \\
\begin{array}{c}\text { Pre- } \\
\text { intervention }\end{array}\end{array}$ & $\begin{array}{c}\text { Between } \\
\text { Groups }\end{array}$ & 257.358 & 3 & 85.786 & 1.871 & .138 \\
\cline { 2 - 7 } & $\begin{array}{c}\text { Within } \\
\text { Groups }\end{array}$ & 5318.567 & 116 & 45.850 & & \\
\cline { 2 - 7 } & Total & 5575.925 & 119 & & & \\
\hline
\end{tabular}

From Table 1 and Table 2 it can be seen that on computing the $F$ ratio it was found that there is no significant difference despite a difference in the means between the four groups. This indicates that all groups were comparable on the variable of perceived stress and all groups had similar levels of perceived stress at pre-intervention level.

Table 3: Mean baseline scores of the four groups on the variable of perceived stress at post-intervention level

\begin{tabular}{|c|c|c|c|l|l|l|}
\hline \multicolumn{7}{|c|}{ Descriptives } \\
\hline & N & Mean & SD & Minimum & Maximum \\
\hline \multirow{2}{|c|}{$\begin{array}{c}\text { Perceived } \\
\text { Stress. } \\
\begin{array}{c}\text { Post- } \\
\text { intervention }\end{array}\end{array}$} & H - Reiki & 30 & 23.23 & 6.02 & 8 & 34 \\
\cline { 2 - 7 } & D-Reiki & 30 & 22.97 & 7.20 & 9 & 41 \\
\cline { 2 - 7 } & D-R Placebo & 30 & 27.10 & 7.93 & 9 & 52 \\
\cline { 2 - 7 } & Control & 30 & 26.47 & 5.51 & 16 & 35 \\
\hline
\end{tabular}


Table 4: Shows the $\mathrm{F}$ ratio for perceived stress at post intervention level

ANOVA

\begin{tabular}{|c|c|l|l|l|l|l|}
\hline \multicolumn{2}{|c|}{} & $\begin{array}{c}\text { Sum of } \\
\text { Squares }\end{array}$ & df & $\begin{array}{c}\text { Mean } \\
\text { Square }\end{array}$ & F & Sig. \\
\hline $\begin{array}{c}\text { Perceived } \\
\text { Stress. } \\
\begin{array}{c}\text { Post- } \\
\text { intervention }\end{array}\end{array}$ & $\begin{array}{c}\text { Between } \\
\text { Groups }\end{array}$ & 414.092 & 3 & 138.031 & 3.045 & 0.032 \\
\cline { 2 - 7 } & $\begin{array}{c}\text { Within } \\
\text { Groups }\end{array}$ & 5258.500 & 116 & 45.332 & & \\
\cline { 2 - 7 } & Total & 5672.592 & 119 & & & \\
\hline
\end{tabular}

\section{From}

Table 3 and Table 4 it can be seen that on computing the $F$ ratio it was found that there is a significant difference between the mean scores of the groups on the variable of perceived stress at post-intervention level. This indicates a trend in the reduction of perceived stress across the groups.

Table 5: Comparison of within the group means of the Hands on Reiki group, Distance Reiki group, Distance Reiki Placebo group and Control group at pre and post assessment on Perceived Stress Scale (PSS)

\begin{tabular}{|c|c|c|c|c|}
\hline Group & Variable & Mean & SD & t \\
\hline Hands on Reiki & PSS. Pre & 30.07 & 6.812 & $4.851^{* * *}$ \\
\hline & PSS. Post & 23.23 & 6.021 & \\
\hline Distance Reiki & PSS. Pre & 26.27 & 5.759 & $2.074^{*}$ \\
\hline & PSS. Post & 22.97 & 7.199 & \\
\hline $\begin{array}{c}\text { Distance Reiki } \\
\text { Placebo }\end{array}$ & PSS. Pre & 29.53 & 7.262 & 2.039 \\
\hline & PSS. Post & 27.1 & 7.928 & \\
\hline Control & PSS. Pre & 28.23 & 7.147 & 1.841 \\
\hline & PSS. Post & 26.47 & 5.513 & \\
\hline
\end{tabular}

*** Significant at 0.001 level

*Significant at 0.05 level

Table 5 shows the pre and post assessment scores for the 3 intervention groups namely, hands on reiki, distance reiki and distance reiki placebo along with the control group on the outcome measure of perceived stress. For the hands on reiki group the mean score for PSS at pre-intervention level was 30.07 and $\mathrm{SD}=6.812$, the mean post-intervention score was 23.23 and $\mathrm{SD}=6.021$ respectively. For the distance reiki group the mean score for PSS at pre-intervention level was 26.27 and SD=5.759, the mean post-intervention score was 22.97 and $\mathrm{SD}=7.199$ respectively. For the distance reiki placebo group the mean score for PSS at pre-intervention level was 29.53 and $S D=7.262$, the mean post-intervention score was 27.10 and $\mathrm{SD}=7.928$ respectively. For the control group no intervention was given. The mean score for PSS at preassessment level was 28.23 and $S D=7.147$, the mean post-assessment score was 26.47 and $S D=5.513$ respectively.

Computed $t$ values were found to be statistically significant for hands on reiki 4.851 at 0.001 levels thereby indicating reduction in perceived stress due to the intervention. t value computed for distance reiki was 2.074 and is significant at 0.05 levels. This indicates that perceived stress reduced for this group due to the intervention as well. $t-$ tests were computed for the distance reiki placebo group and control group, both $t$ 
values were found to be statistically not significant. This indicates that distance reiki placebo had no effect on perceived stress and there were no significant changes within the control group with respect to pre assessment and post assessment of perceived stress.

\section{DISCUSSION}

\subsection{Hands on Reiki Intervention}

The first objective of this study was to check the efficacy of Hands on Reiki on perceived stress of software professionals. Before the intervention both the hands on reiki group and the control group had similar scores on perceived stress. Paired $t$ tests demonstrated significant group differences on perceived stress for the hands on reiki group, on completion of the 21 day hands on reiki intervention period. These findings are in consensus with the study of Shore AG (2004) who explored the long-term effects of energetic healing on symptoms of psychological healing and self-perceived stress. In this study participants were healed by hands on reiki, distance reiki and placebo reiki separately. Results showed that Hands on Reiki too had a significant effect on reducing stress in comparison with the control group. The findings are further supported by results from a pilot study by Cuneo CL et al (2011). The effect of Reiki on work related stress of nurses was analysed. Perceived stress scale was used as a tool for pre and post assessment. It was concluded that practising Reiki more often by nurses can reduce perceived stress levels. This also indicates that the duration of intervention of 21 days as used in the current study, which is the usual time frame used by reiki practitioners to check if reiki works for their clients is sufficient to bring down stress of the participants of the hands on reiki group. The results of this study are in congruence with the study done by Baldwin A.L et al (2008), where in the effect of Reiki was tested on the heart rate homeostasis in noise stressed laboratory rats. It was concluded that Reiki is effective in modulating HR in stressed and unstressed rats, supporting its use as a stress-reducer in humans. The positive results of the current study can be attributed to the healing ability of touch. There is a lot of scientific evidence for the healing ability of touch on stress indicators like anxiety, glucose metabolism, blood pressure and heart rate. As Hands on Reiki uses touch as a medium to heal, it is similar to touch therapy and tactile touch intervention. The efficacy of touch therapy further accentuates to the efficacy of Hands on Reiki as well (Henricson. $M$ et al 2008). Most CAM modalities are quoted to be efficient based on the concept of the patient's belief (Astin, J.A.1998). The results of the current study could be due to the sample's belief in the healing power of Reiki. The current findings conflict results of a study by Witte, D et al (2001) where in the study examined deficiencies in existing Reiki research by objectively measuring the effect of Reiki on physical and mental relaxation. It was concluded that there were no pre-test post-test differences on mental relaxation compared to other therapies. There was significant effect only for physical relaxation. The present results support findings of Wardell and Engebretson (2004). In their study the effect of Reiki on biological markers of stress and anxiety was analysed. Results concluded that Reiki has a significant effect in reducing anxiety and decreasing systolic blood pressure thereby indicating a significant reduction in stress.

The current findings and supportive studies mentioned indicate that Hands on Reiki can significantly reduce perceived stress.

\subsection{Distance Reiki Intervention}

The second objective of this study was to check the efficacy of Distance Reiki on perceived stress of software professionals. Before the intervention both the distance reiki group and control group had similar scores on perceived stress. On completion of the 21-day distance reiki intervention period, paired t tests demonstrated significant group differences on perceived stress for the distance reiki group. These findings are in consensus with the study of Shore AG (2004) who explored the long term effects of energetic healing on symptoms of psychological healing and self-perceived stress. In this study participants were healed by hands on reiki, distance reiki and placebo reiki separately. Results showed that Distance Reiki too had a significant effect on reducing stress in comparison with the control group. The present findings is further supported by the study of Crawford et al (2002) which revealed that distance healing intervention studies scored better than hands on healing studies. However, the current finding conflicts as the systematic review by Astin Ja et al (2000) of available data on the efficacy of any form of distance healing. It was noted that it was difficult to draw a conclusion about the efficacy of distance healing, however more than $57 \%$ of trials showed a positive treatment effect. With the usual fast paced life of software professionals Distance Reiki has a higher preference than hands on reiki due to various convenience factors like, the recipient does not need to go to the reiki practitioner's reiki studio or clinic to receive Reiki, as time and space is no constraint for distance reiki the recipient can receive reiki healing at any time during the day at any place in the world also there are no rigid dietary restrictions to be followed to receive reiki unlike other CAM modalities like yoga and Ayurveda. These convenience factors can be considered as contributing reasons for the effectiveness of 
distance Reiki in this study.

\subsection{Distance Reiki Placebo intervention}

The third objective of this study was to check the efficacy of Distance Reiki placebo on perceived stress of software professionals. No reiki intervention was given for this group; however, the participants were informed that they would be healed. This was done to induce the placebo effect and also to ensure that there would be not extraneous variable which would interfere with the study thereby maintaining likelihood that significant differences could exist post treatment which could be attributed to the distance reiki placebo intervention. On completion of the 21-day distance reiki placebo intervention period, paired t tests demonstrated no significant group differences on perceived stress for the distance reiki placebo group. This indicates that the power of belief in a healing CAM modality like Distance Reiki cannot elicit a change in a psychological variable like perceived stress. The results of the current study are supported by findings from a similar study by Witte and Dundes (2001) who studied the effectiveness of Reiki on physical and mental relaxation with a convenience sample of 100 undergraduate students on a college campus. No significant differences were found. The results of this study could be because of insufficient sample size, potential error variance in pre-test relaxation state, and 20-minute sessions for relaxation. The results of the current study are further supported by a study conducted by Diaz R et al (2011) on the immediate effects of reiki on heart rate variability, cortisol levels and body temperature in health professionals with burnout. These results suggest that Reiki has an effect than the placebo arm on the parasympathetic nervous system. A systematic review by Ernst, E. (2003) on distant healing concluded that there is ample evidence to prove that distance healing is more than a placebo. This review contradicts the results of the current study. The current findings are reinforced by the results of a study by Shiflett et all, where double blind placebo control design was used to investigate effects of reiki on subacute ischemic stroke patients. Results showed no evidence of short term benefits. Placebos work solely on the power of belief. This study proves that despite verbally assuring the participants in the experimental group had they would be healed to reduce their perceived stress, their belief in the reiki practitioner and distance reiki healing did not facilitate the placebo effect. The results could also be because of insufficient sample size and participant's lack of belief about the efficacy of distance reiki healing could have contributed the unsuccessful outcomes.

\section{CONCLUSIONS}

Stress is usually treated with psychiatric counselling and medication. The current study reveals that Hands on Reiki and Distance Reiki reduces perceived stress as compared with controls. Distance Reiki Placebo has no effect in reducing perceived stress. The benefit of Hands on Reiki and Distance Reiki are proven to be effective with five minutes healing daily over a brief period of twenty-one days for software professionals. The results of this study demonstrate that Hands on Reiki and Distance Reiki can be used as an effective treatment to handle stress and there is scope for future research in this domain.

\section{REFERENCE LIST}

Astin, J. A. (1998). Why patients use alternative medicine: results of a national study. Jama, 279(19), 15481553.

Astin, J. A., Harkness, E., \& Ernst, E. (2000). The efficacy of "distant healing": a systematic review of randomized trials. Annals of internal medicine, 132(11), 903-910

Baldwin, A. L., Wagers, C., \& Schwartz, G. E. (2008). Reiki improves heart rate homeostasis in laboratory rats. The Journal of Alternative and Complementary Medicine, 14(4), 417-422.

Crawford, C. C., Sparber, A. G., \& Jonas, W. B. (2002). A systematic review of the quality of research on hands-on and distance healing: clinical and laboratory studies. Alternative therapies in health and medicine, 9(3 Suppl), A96-104.

Cuneo, C. L., Cooper, M. R. C., Drew, C. S., Naoum-Heffernan, C., Sherman, T., Walz, K., \& Weinberg, J. (2011). The effect of Reiki on work-related stress of the registered nurse. Journal of Holistic Nursing, 29(1), 33-43.

Díaz-Rodríguez, L., Arroyo-Morales, M., Fernández-de-las-Peñas, C., García-Lafuente, F., García-Royo, C., \& Tomás-Rojas, I. (2011). Immediate effects of reiki on heart rate variability, cortisol levels, and body temperature in health care professionals with burnout. Biological Research for Nursing, 1099800410389166.

Ernst, E. (2003). Distant healing-an "update" of a systematic review. Wiener Klinische Wochenschrift, 
115(7-8), 241-245.

Henricson, M., Ersson, A., Määttä, S., Segesten, K., \& Berglund, A. L. (2008). The outcome of tactile touch on stress parameters in intensive care: a randomized controlled trial. Complementary therapies in clinical practice, 14(4), 244-254.

Shiflett, S. C., Nayak, S., Bid, C., Miles, P., \& Agostinelli, S. (2002). Effect of Reiki treatments on functional recovery in patients in poststroke rehabilitation: a pilot study. The Journal of Alternative \& Complementary Medicine, 8(6), 755-763.

Shore, A. G. (2003). Long-term effects of energetic healing on symptoms of psychological depression and self-perceived stress. Alternative therapies in health and medicine, 10(3), 42-48

Wardell, D. W., \& Engebretson, J. (2001). Biological correlates of Reiki Touchsm healing. Journal of advanced nursing, 33(4), 439-445.

Witte D. \& Dundes L. [2001] Harnessing Life Energy or Wishful Thinking?: Reiki, Placebo Reiki, Meditation and Music, Alternative and Complementary Therapies, vol 7, no 5, pp304-309

Witte, D., \& Dundes, L. (2001). Harnessing life energy or wishful thinking? Reiki, placebo reiki, meditation, and music. Alternative \& Complementary Therapies, 7(5), 304-309. 